\title{
Research Student Supervision: An Approach to Good Supervisory Practice
}

\author{
Norhasni Zainal Abiddin ${ }^{*}, 1$, Aminuddin Hassan ${ }^{1}$ and Abdul Razaq Ahmad ${ }^{2}$ \\ ${ }^{I}$ Faculty of Educational Studies, Universiti Putra Malaysia \\ ${ }^{2}$ Faculty of Education, National University of Malaysia
}

\begin{abstract}
Good supervisory practices help students fulfill their potential and contribute to the University's research profile. At many universities, the terms of a supervisory relationship are left almost entirely to the discretion of individual research students and supervisors. While this approach usually works well, it occasionally proves unsatisfactory. A lack of clarity between student and supervisor with regard to expectations and responsibilities can adversely affect progress towards the completion of the degree. This article reviews the literature on research/graduate student supervision. It describes best practices in research student supervision, and setd out the rights and responsibilities of both students and their supervisors. It is intended to provide some useful guidelines for research students and supervisors in a critically important part of graduate education: the supervision of students' thesis writing and research. Therefore, a review of literature concerning research student supervision is hoped to assist all participants in the supervisory process to articulate their expectations clearly, and thereby to reduce potential problems and to facilitate the creative process of thesis preparation.
\end{abstract}

Keywords: Graduate, Ph.D, research student, supervision, supervisor, thesis.

\section{INTRODUCTION}

Numerous researchers have pointed out that there are a high proportion of $\mathrm{Ph} . \mathrm{D}$ students who fail to complete their studies in the UK. The most frequently cited reasons are problems with supervision [1-9]. According to Russell [10], the examination of supervision has the potential to make an important contribution to the quality of postgraduate research.

Supervision is widely recognized as being complex and multidimensional. Ballard and Clanchy [11] describe research student supervision as a blend of academic expertise and the skilled management of personal and professional relations. Some writers, such as Binns and Potter, Hockey [12-13] discuss the patterns and process of supervision and especially the roles of postgraduate students in producing effective supervision. In view of this research, effective supervision of research students is acknowledged to be a crucial factor in the latter's successful completion of the Ph.D [14]. How well they are supervised is likely to be linked to the way they choose to occupy their role. This kind of experience is very interesting and meaningful to appropriate persons like students, supervisors and schools in order that they may examine what they should do and how they should go about playing their roles optimally. Kiley and Austin [15] studied the mobility of postgraduate students in Australia. One of the reasons that led to making a choice the university was related to supervision.

There are at least three important aspects that the student and supervisor should take into account in order to achieve success in the student's Ph.D, namely the responsibilities of

*Address correspondence to this author at the Department of Professional Development and Continuing Education, Faculty of Educational Studies, Universiti Putra Malaysia; E-mail: nonie@ace.upm.edu.my an effective supervisor, the responsibilities of the research students and their relationship with their supervisors. This article focuses on one-to-one or student-supervisor relationship and their responsibilities. Even though the more recent trend is try to suggest that the relationship between student and supervisor could be better understood considering wider social aspects. There is intensity on the one-to-one supervision because it is probably going to be a lot of investment of importance, by both sides; into what they are doing that will develop the close trust.

\section{LITERATURE REVIEW AND DISCUSSION}

\section{The Responsibilities of an Effective Supervisor}

Haksever and Manisali [16] mention that, as Ph.D programs in the British education system are not based on formal lectures and credits, the supervision requirements of $\mathrm{Ph} . \mathrm{D}$ students in the UK are generally greater than those who study under more formal and structured programs, as is the case in the US and Europe. Therefore, the role of the Ph.D supervisor in the British education system is critical to a successful $\mathrm{Ph} . \mathrm{D}$ process. Poor supervision can have a significant impact on students, not only limiting the quality of their work, but also their motivation.

There are many opinions regarding the responsibilities of supervisors. Most of all, the supervisor should give constant support and reassurance to the student [16-20] and keep the student's morale high [18]. Russell [10] undertook a study in the Faculty of Education, Humanities, Law and Theology at The Flinders University, South Australia to understand postgraduate research by interviewing research students and supervisors. This study found that nearly half of the students who participated felt that the constraints they encountered related to lack of support from the supervisor. These included a lack of encouragement, pastoral care and reassurance from the supervisor. Cryer and Salmon $[21,22]$ support this statement, pointing out that a supervisor should support 
students by emphasizing pastoral care and providing advice, sympathy and encouragement. The supervisor should know where to refer students when serious personal problems begin to affect their work [23]. According to Brown and Krager [24], the supervisor also needs to be sensitive to students' time and competence limitations, and to assist them to become aware of their own limitations and any constraints on them.

The supervisor performs a variety of tasks, many only remotely related to monitoring and improving performance [25-28]. Supervisors are expected to be mainly experts in teaching [24-26, 28-33]. Many tasks of supervisors are related broadly to advice [34]. Advice is given on direction, completeness, clarity, methodology, topic selection [35] and feedback is given on progress of written work [10, 34]. According to Spear [35], feedback is normally given in relation to topic selection, methods of inquiry, writing style and layout, the clarity of the student's work and ideas, the completeness and direction of the work, and the student's general progress. Also, advice on the desirable amount of reading, experimentation and analysis will normally be expected [36]. Spear [35] states that supervisors should read the student's written work thoroughly and provides constructive criticism, since this is an essential element in the student's intellectual development. However, a major student complaint is that supervisors have been unduly slow in reading thesis drafts and other written material.

Russell and Moses [10, 17] found that both supervisors and students agreed that one role of the supervisor was to assist students in general. The amount of assistance that supervisors give to graduate students varies, depending upon the stage that the latter have reached [17]. Supervisors believed that they were contributing by organizing help with skills, developing English writing, by collecting relevant literature and through networking or putting students in contact with others working in the area [37]. Salmon [22] also argues that students need substantial help in achieving an appropriate orientation for the final oral examination. The supervisor should also provide sufficient time to student to think about the work and freedom to adopt a trial and error approach during early attempts to get started [18, 21] and also the motivation $[28,34,38]$. As the research progresses, supervisors need to become involved in stimulating as much creative thinking as possible among students in an attempt to foster their development [13].

Hockey [13] points out that this process should be open to negotiation and Bargar and Mayo-Chamberlain [39] propose that it should be open to change. Connell [29] argues that it is incumbent upon the supervisor to bridge gaps in communication during the various stages of research by requesting regular meetings or updates. He finds that as research progresses, students move from looking to supervisors for direction and guidance towards forming a critical friendship. Moses [17] argues that at each stage of the research progress, students are likely to need different forms of guidance. They need a particular guidance on when to stop data collection and analysis, when to start drafting the thesis and how to structure it [17]. Thus, the supervisors are expected and assumed to be guides $[10,19,21,22,24,28,38]$ and critical friends $[13,40]$. On the other hand, they should also be able to adopt flexible supervision strategies depend- ing on the individual requirements, which are influenced by the attributes of the particular student [13, 24, 41, 42]. This is due to the fact that Ph.D students are not homogenous, but highly diverse in terms of academic ability, personality attributes, motivation and attitude. Hence, how supervisors respond to students will, in part, be conditioned by these different factors and applying the same rigid strategy for each student may not always work effectively [42]. Burgess, Pole \& Hockey [43] also pick up the theme of changing research stages and the need for a supervisor to be flexible in an attempt to meet the needs of individual students. Supervisors who have this flexibility can be more helpful to their research students [16]. Hockey [13] agrees with this statement and suggests that supervisors initiate a tight structure of control solely with the students whom they consider to be weak. However, research has found that strong and highly motivated students also demand such a structure. Conversely, with this kind of student, supervisors might need considerable latitude in order to express themselves intellectually. In this case, a relatively unstructured strategy might develop with supervisors being primarily reactive to students' demands.

Haksever and Manisali [16] define the supervisory requirements of the student as follows: (1) personal help: support, motivation, socializing, help in organizing accommodation and other things that may be required, but are unrelated to the research; (2) indirect research related help: providing contacts, both industrial and academic, providing equipment and initial help in locating references; and (3) direct research-related help: critical analysis of work, help with methodological problems, precise direction and help with the management of the project. The results also show that the most personal help was required by the overseas contingent [16]. Welch [44] suggests three styles of supervision. Firstly, she described the highly directive approach, which is very structured with the student being given a lot of advice in the early stages. This level of control diminished as the student gained a confidence and ability. The second approach is highly directive at the beginning and the end of the project with a highly non-directive period in the middle. Finally, the third approach was described as highly directive with close monitoring of the student throughout the project.

Spear [35] concludes that one of the most common complaints from research students concerns infrequent or erratic contact with supervisors, who may be too busy with administrative or teaching responsibilities, have too many students or be away from the university too often. Therefore, the supervisor should make equal information, time and energy available to all students [24] and should also meet regularly with students $[10,13]$. Research has shown that constant, thoughtful supervision and availability is the key to successful graduate programed completion $[34,45]$. Other important responsibilities of supervisors include making sure that they are aware of matters such as requirements for thesis preparation, reporting and review requirements throughout their course, availability of resources for conference attendance and fieldwork, departmental policies on photocopying, computing access, fax and e-mail, procedures for extension of course and suspension, the availability of counseling and study skills support, and institutional policy on the ownership of intellectual property. Such advice is, of course, especially useful for international students [10]. 
Effective supervision requires supervisors to be knowledgeable and skilled in the research field [34, 40, 42, 46]. They are also expected to take the lead in establishing a quality of relations which will give their students access to the knowledge and skills they possess [11] and to have counselling skills [23, 47]. Students expect their supervisors to have the knowledge and ability to supervise in a particular area of research but also want them to be reasonable, serious, supportive of their work in good times and bad, and approachable [4]. Moses [17] considers that supervisors should act as mentors and that a mentoring relationship requires mutual respect based on high academic standards, similar interests and regular contact. According to Moses [4], supervisors should at least have an equivalent degree to the one the student is studying for and, if this is not the case then, they must have a solid background of research involvement and publications. Brown and Atkins [37] suggest that, to supervise effectively, one has to be a competent researcher and to be able to reflect on research practices and analyse the knowledge, techniques and methods that make them effective. Frischer \& Larsson [14] and Phillips \& Pugh [18] take a slightly different view, in that they suggest that students are recommended to select a supervisor based on the key factor of whether the latter has an established research record and is continuing to contribute to the development of his or her discipline. This includes whether the person has recently published research, holds research grants and is invited to speak at conferences in their own country or abroad. Therefore, an effective supervisor should satisfy such criteria. Spear [35] supports this statement and adds that often it will be sufficient for the supervisor to be competent in the general area of the student's research even if not expert in the detailed area of the thesis topic. Yeatman [48] gives a similar view, stating that good supervisors must have a track record in successfully bringing through a large number of Ph.D candidates.

According to Burton and Brueckner [27], the primary function of supervisions of all types is the leadership, plus the encouragement and recognition of leadership in other people, either on the professional staff or among community participants. On the other hand, Phillips \& Pugh and ZuberSkerrit $[18,23]$ advised supervisors to act as role models. Frischer and Larsson [14] describe three different patterns of leadership, which they call democratic, authoritarian and laissez-faire. The democratic leader is characterised by his encouragement of group discussions and group decisions in the choice of activities. He cares for the students by checking their achievements and commenting upon them. The authoritarian leader makes major decisions for the group all by him and shows it what to do. The laissez-faire leader provides the students complete freedom of action, hands out materials but largely avoids participating in work and checking and does not evaluate and comment upon their work, except when asked. The authoritarian leader was found to achieve a greater quantity of work, the democratic a greater quality of work, while laissez-faire leadership resulted in both a low quantity and quality of work.

Good supervisors seem to have many of the same qualities of good lecturers and good counsellors. They are empathic, genuine, open, and flexible. They respect their supervisees as persons and as developing professionals, and are sensitive to individual differences (e.g. gender, race, and ethnicity) of supervisees. They also are comfortable with the authority and evaluative functions inherent in the supervisor role, giving clear and frequent indications of their evaluation of the supervisee's performance. Even more, good supervisors who really enjoy supervision, are committed to helping the supervisee grow, and evidence commitment to the supervision enterprise by their preparation for and involvement in supervision sessions. Finally, good supervisors have a sense of humour which helps both the supervisor and supervisee get through rough spots in their work together, and achieve a healthy perspective on their work. Such personal traits and relationship factors are considered as significant as the technical prowess in supervision. Perhaps surprisingly, comparison studies have yielded few differences between novices and experienced supervisors. In general, more experienced supervisors seem to use more teaching and sharing behaviours, and they and their supervisees are more active. Ratings of effectiveness, however, find novices to be equally effective as experienced supervisors [49].

\section{The Responsibilities of Research Students}

Phillips and Pugh [18] point out that the acquisition of skills by postgraduate students should be effected as professional learning conducted under their own management. In other words, research students have to take responsibility for managing their own learning and getting a Ph.D. They are also responsible for determining what is required as well as for carrying it out, and must always keep in touch in regular meetings with the supervisor [17, 46]. Moses [4] argues that supervisors expect students to be diligent, hardworking, energetic, keen, tenacious and conscientious and to have a sense of urgency. They also expect students to be enthusiastic and motivated towards research work, to be pleasant at work and to contribute to a good working environment. Also, students should give continual feedback, so that the supervisor can give informed instruction.

The student is the main person responsible for his/her $\mathrm{Ph} . \mathrm{D}$ research. Doing a Ph.D clearly indicates that this is a student's own research and work. Phillips and Pugh [18] emphasise that it is the student's responsibility to determine what is required as well as carrying it out, and that students have to come through with the clear aim of becoming a competent professional researcher. In other word, it is agreed that the student is responsible for an original contribution to the subject and for developing a mature, critical knowledge of the subject area and its context. It is also a good idea for them to talk to other postgraduates about their experience of the role as well as their work. Russell [10] found that one of the highly rated constraints on research students' are personal problems. In fact, sharing apprehensions helps to resolve problems through the knowledge that the problem is not an individual one $[18,50]$. Once students are able to share feelings and talk about them and their effect on their work, they will all start to feel better [10].

Students should identify the topic and preliminary reading [24]. This can be linked with other parts of the Ph.D task, like the development of a relevant body of knowledge, placing the research in the context of the literature and originality $[19,16,22]$. Moses and Phillips \& Pugh [4, 18] elaborate this statement mentioning that the process of defining the research topic varies across disciplines. The supervisor in a 
science discipline has to take the lead in obtaining the physical resources and the research personnel required. The student's research topic will be clearly defined to fit in with the innovative thrust of the supervisor's research program. In contrast, in the humanities and social sciences, students often come with their own topics within the field in which the supervisor is expert. Additionally, after surveying aspects of graduate education in Canadian universities, Holdaway et al. [36] report that in education, social sciences and humanities, graduate students choose their thesis topics themselves more frequently than those in other disciplines do.

The thesis is usually the most substantial piece of writing yet undertaken by students, and it provides an opportunity for them to develop their skills in writing and in marshalling arguments [16]. On the other hand, they should submit written work in some form as early as possible in their studies so that writing problems can be recognized and corrected [35]. According to Haksever and Manisali [16], they should also decide on the research problem, designing the methodology and examination. Donald et al. [34] propose that the responsibilities of the student should include understanding the scope of doctoral work, such as the number of years to be devoted to full time study, knowledge of research methods necessary to carry out studies, the regulations on thesis submission and the expectations of the supervisor regarding every aspect of the research.

A good student should have a broader view of academic training in the discipline in which he/she is undertaking the research, seeing it as professional development [18]. In this sense, professional development include attending conferences, writing papers for publication, attending seminars and workshops, making presentations, networking with other researchers, working as a research assistant and teaching $[18,24,26,36]$. Students are expected to gain expertise in the research process so that their talents can be observed in as many different settings as possible [24].

Most overseas students are sponsored by appropriate bodies during their study. They have been given a specific period, namely three years, to complete their study and return to their own country. Therefore, time is one of the enemies of the overseas student. This is relevant to the study conducted by Russell [10], who found that students are concerned about time and time management. Lack of funding seriously affects some students' research, or requires them to partly self-fund it and this result in serious concerns and deep frustration $[36,51]$. This view is supported by the Economic and Social research Council (ESRC) which reported that less than 20 percent of students receiving a grant complete their study within four years, while 27 percent complete within five years and that completion rates trailed off markedly after five years [52]. Therefore, students are expected to work within deadlines $[18,22,48,53]$ and to have a planned timetable $[5,14,54]$.

\section{Relationship with their Supervisor}

A literature search has provided evidence that the student/supervisor relationship is vital to the Ph.D process. The literature includes statements about the single most important problem, in the eyes of many respondents, being the quality of supervision [1]. Various books have approached the acquisition of Ph.Ds, including the management of the supervisor/student relationship [18] and many departments carry out their own surveys in an attempt to assess their performance in the supervision of their students [16].

The responsibility for completing a Ph.D within a reasonable length of time clearly depends on both the student and the supervisor $[16,42,48,53,55,56]$. Both of them should play their role effectively and maintain a good relationship during the period of the program $[4,35,38,46,57$ 59]. The relationship can be seen as a personal and professional relationship between the two $[11,13,39,48,60]$. This relationship is dependent upon the characteristics of the persons involved, disciplinary differences in the ways knowledge is advanced and the different learning tasks facing students due to the demands of their field. The relationship between the student and supervisor involves selecting a research topic, planning the research, identifying and acquiring the necessary resources, managing the project, actively conducting the research, carrying out the literature review, analysis and interpretation of the data, writing the thesis, defending it and possibly publication [60]. Consequently, the supervisory process requires constant adjustment, great sensitivity and interpersonal skill on the part of both the supervisor and student [13, 47, 60].

Good communication between students and their supervisor is the most important elements of supervision [13, 16, $18,24,28,34,35,39,42]$. Without open and honest communication it is very difficult to identify the nature of and reasons for the shortfalls perceived by the student. Both parties should be open to criticism, willing to listen to each other and to talk openly [16] and trustworthy [13, 22, 61]. According to Donald et al. [34], personality factors might involve personality clashes, barriers to communication due to age, cultural, or language differences, or personal differences in the approach to work. Therefore, students bear their own degree of responsibility in dealing with these clashes.

Surveys have been conducted by the University of British Columbia to gain information about the experiences of graduate students [62]. They show that generally, students feel satisfied with their supervisor, but the international students are more likely to meet regularly with their supervisors. Spears [35] states that some universities have established formal requirements for regular meetings between supervisors and students and for the establishment of adequate arrangements for supervision when the supervisor is away for an extended period. Spear [35] also mentions that the frequency of meetings can vary by mutual consent as the course progresses. Clearly, the nature of the studentsupervisor relationship will be influenced by the duration of the research, the level of research undertaken and the stage the student is at in the research project [42].

During the meeting with supervisor, the student normally suggests having a graduate student $\log$. This $\log$ involves the student writing up what is transacted in the supervision meeting. It should end with a response to "where to from here?' The $\log$ is an invaluable resource in the early stages of a graduate research thesis project when a great deal of structure is needed to get the process going and the topic focused. The graduate supervision $\log$ is an example of using new contractualist technologies of management to make the supervision relationship rationally accountable in ways which are likely to facilitate successful graduate student completion 
of the task. This will need the explicit skill of graduate students in all the competencies and knowledge that go into the successful production of a Ph.D thesis [48].

\section{CONCLUSION}

The supervision process is a complex teaching task, requiring a substantial commitment of time and energy by both supervisor and student. A review of graduate student supervision literature indicates that there is no one formula for the supervisor-student relationship; it is dependent upon the characteristics of the persons involved, disciplinary differences in the ways knowledge is advanced, and the different learning tasks facing students due to the demands of their field. There are, nonetheless, two aspects which should be considered when developing a 'best practices' model for graduate student supervision.

The first aspect has to do with creativity and involves supervision as a process which is open to negotiation and change. Several supervision studies have observed that there are loosely defined stages common to most research projects. Thus, the roles expected and assumed by students and supervisors; as guide, project manager, or 'critical' friend, structure the relationship and the strategies for supervision.

The second aspect of supervision is concerned with the mechanics of ensuring that the student makes good progress toward completion. On the other hand, the supervision literature indicates that ethical, technical and methodological problems can be minimized or prevented if all the participants in the relationship strive to enter it with clear expectations for their respective roles and about the rules for their interactions. Therefore, both on a departmental and individual basis, the supervisor must be diligent about explicitly working with students to establish mutual expectations, responsibilities and benefits for working together.

Students must also be proactive to facilitate communication processes and the development of professional competence. Some suggestions for the supervisory framework for supporting and defining the student's graduate program include producing a definite plan in writing, probably different for each department, that describes the department's view on good supervisory practice; establishing regular meetings between student and supervisor; and setting up adequate methods of assessing course work, and thesis or dissertation supervision record-keeping and project advancement.

It was asserted that the paper was focused on the one-toone or student-supervisor relationship and their responsibilities, even when it is recognized that there are other aspects affecting the Ph.D students' education. Perhaps the decision has been taken, given the limitations of research on this topic to consider a more holistic view. In reality, research students also must have good relationship with their supervisory committee members and with peers (students who have been given same supervisor) and it is doubt that the studentsupervisor relationship is normally developed through regular meetings. It was based on the fact that, meetings with supervisor is part of the practices for any postgraduate research students. Therefore, further research should focus on individual, group and committee meetings by looking at few elements such as: the organization and format of the meetings; the purpose of the meeting, the topics or content of the meetings, the frequency of the meetings, the structure of session, the contribution and also the characteristics of feedback of those meetings. Among others, the research questions should include: How did the combination of student supervision meetings function as support for postgraduate students' research? And what were the potential, problems and special contribution of each arena? This kind of research could enhance the effectiveness of the supervision due to there has been an increased focus on improving supervision practices.

\section{REFERENCES}

[1] Buckley PJ, Hooley GJ. The non-completion of doctoral research in management: symptoms, causes and cures. Euro J Eng Educ 1988; 25(1): 19-32.

[2] Delamont S, Eggleston J. A necessary isolation? Qual Stud Educ 1983; 9(4): 481-500.

[3] Marsh A. Postgraduate students' assessment of their social science training (SSRC Survey Unit Occasional Paper No. 2). London: social science research council 1972.

[4] Moses I. Supervision of higher degree students- problem areas and possible solutions. High Educ Res Devel 1994; 3: 153-65.

[5] Rudd E. A new look at postgraduate failure. High Educ 1985; 28(1): 483-98.

[6] Smith R. Research degrees and supervision in polytechnics. J Furth High Educ 1989; 13(1): 76-83.

[7] Welsh JM. The first year of postgraduate research study. Guildford: Society for Research into Higher Education (SRHE) 1979.

[8] Winfield G. The social science Ph.D, the ESRC inquiry on submission rates: the report. London: Economic and Social Research Council 1987.

[9] Wright J, Lodwick R. The process of the Ph.D: a study of the first year of doctoral study. Res Pap Educ 1989; 4: 22-56.

[10] Russell A. Postgraduate research: student and supervisor views. The Flinders University of South Australia 1996.

[11] Ballard B, Clanchy J. Supervising students from oversees. Can J High Educ 1993; XXV (3): 1-29.

[12] Binns T, Potter R. Improving the effectiveness of postgraduate supervision: never mind the quality, feel the width. J Geogr High Educ 1989; 13(2): 210-16.

[13] Hockey J. Strategies and tactics in the supervision of UK social science Ph.D students. Qualit Stud Educ 1996; 9(4): 481-500.

[14] Frischer J, Larsson K. Laissez-faire in research education - An inquiry into a Swedish doctoral program. High Educ Policy 2000; 13(2): 132-55.

[15] Kiley M, Austin A. Australian postgraduate students' perceptions, preferences and mobility. High Educ Res Dev 2000; 19(1): 75-88.

[16] Haksever AM, Manisali E. Assessing supervision requirements of Ph.D students: the case of construction management and engineering in the UK. Euro J Engin Educ 2000; 25(1): 19-32.

[17] Moses I. Good Supervisory practice. Can J High Educ 1992; XXV (3): 1-29.

[18] Phillips EM, Pugh DS. How to get a Ph.D - a handbook for students and their supervisors. Buckingham: Open University Press; 2000.

[19] Sheehan J. Issues in the supervision of postgraduate research students in nursing. J Adv Nurs 1993; 18: 880-85.

[20] Slick SK. The university supervisor: a disenfranchised outsider. Teach Teacher Educ 1998; 14(8): 821-34.

[21] Cryer P. The research student's guide to success. Buckingham: Open University Press; 2000.

[22] Salmon P. Achieving a Ph.D- ten students' experience. Staffordshire: Trentham Books Ltd; 1992.

[23] Zuber-Skerrit O. Improving the quality of postgraduate supervision through residential staff development programmes. J Furth High Educ Scotl 1994; 20(1): 23-30.

[24] Brown RD, Krager L. Ethical issues in graduate education: faculty and student responsibilities. J High Educ 1985; 56(4): 403-18.

[25] Ali MA. Supervision for teacher development: an alternative model for pakistan. Int J Educ Dev 2000; 20(3): 177-88.

[26] Alfonso RJ, Firth GR. A research agenda: supervision: needed research. J Curriculum Superv 1990; 5(2): 181-88.

[27] Burton WH, Brueckner LJ. Supervision: a social process. New York: Appleton-Century-Crofts, Inc.; 1955. 
[28] Waitie D. Understanding supervision: an exploration of aspiring supervisors' definitions. J Curriculum and Supervision 1994; 10(1): 60-76.

[29] Connell R. How to supervise a Ph.D. Vestes 1985; 2: 38-41.

[30] Ford K, Jones A. Student supervision. London: Macmillan Education Ltd.; 1987.

[31] Gardiner D. The anatomy of supervision: developing learning and professional competence for social work students. Suffolk: SRHE and Open University Press; 1989.

[32] Satlow ID. Democracy in the Supervision of a High School Department. J Educ Sociol 1959; 32(5): 222-25.

[33] Young PH. The student and supervision in social education. London: Routledge and Kegan Paul; 1967.

[34] Donald JG, Saroyan A, Denison DB. Graduate student supervision policies and procedures: a case study of issues and factors affecting graduate study. Can J High Educ 1995; XXV(3): 71-92.

[35] Spear RH. Supervision of research students: responding to student expectations. Canberra. The Australian National University, 2000.

[36] Holdaway E, Deblois C, Winchester I. Supervision of Graduate Students. Can J High Educ 1995; XXV(3): 1-29.

[37] Brown G, Atkins M. Effective teaching in higher education. London: Methuen; 1988.

[38] Kam BH. Style and quality in research supervision: the supervisor dependency factor. High Educ 1997; 34: 81-103.

[39] Bargar RR, Mayo-Chamberlain J. Advisor and advisee issues in doctoral education. J High Educ 1983; 54(4): 407-32.

[40] Sheehan P. From thesis writing to research application: learning the research culture. J Furth High Educ Scotl 1994; 20(1): 23-30.

[41] Hill T, Acker S, Black E. Research students and their supervisor. J Furth High Educ Scotl 1994; 20(1): 23-30.

[42] McQueeney E. The nature of effective research supervision. J Furth High Educ Scotl 1996; 20(1): 23-31.

[43] Burgess RG, Pole CJ, Hockey J. Strategies for managing and supervising the social science Ph.D. Qualit Stud Educ 1994; 9(4): 481-500.

[44] Welch AJ. The postgraduate student: Progress and problem. Unpublished Ph.D Department of Education, University of Aberdeen. J Furth High Educ Scotl 1980; 20(1): 23-30.

[45] Holdaway EA. Organization and administration of graduate studies in Canadian Universities. Can J High Educ 1991; XXV (3): 71-92.

[46] Powles M. How's your thesis going? Can J High Educ 1989; XXV (3): 1-29.

[47] Hockey J. Getting too close: a problem and possible solution in social science Ph.D Supervision. Br J Guid Counsell 1995; 23(2): 199-210.
[48] Yeatman A. Making supervision relationships accountable: graduate student logs. Aust Univ Rev 1995; 38(2): 9-11.

[49] Borders DL. The good supervisor. ERIC Digest. Retrieved 1994, Nov 13 from website:http://www.eric.ed.gov/ERICDocs/dat a/ericdocs2sq1/content storage 01/0000019b/80/15/c6/77.pdf

[50] Arksey H, Marchant I, Simmill C. Juggling for a Degree - Mature Students' Experience of University Life. Lancaster: Unit for Innovation in Higher Education 1994.

[51] Hofman A, Berg MVD. Determinants of study progress: the impact of student, curricular, and contextual factors on study progress in university education. High Educ Eur 2000; XXV (1): 93-110.

[52] Elton L, Pope M. Social Science Ph.D. Completion Rates. Research Intelligence, BERA Newsletter, February. In: Haksever AM, Manisali E. Assessing supervision requirements of Ph.D. students: the case of construction management and engineering in the UK. Eur J Engin Educ 1987; 25(1): 19-32.

[53] Science and Engineering Research Council (SERC). Research student and supervisor: an approach to good supervisory practice. London: SERC 1983.

[54] Bowen WG, Rudenstine NL. In Pursuit of the Ph.D. Princeton, NJ: Princeton University Press; 1992.

[55] Hockey J. A complex craft: United Kingdom Ph.D. supervision in the social sciences. Res Post-Compul Educ 1997; 2(1): 45-68.

[56] Sayed Y, Kruss G, Badat S. Students' experience of postgraduate supervision at the University of the Western Cape. J Furth High Educ 1998; 22(3): 275-85.

[57] Cullen DJ, Pearson M, Saha L, Spear RH. Establishing effective $\mathrm{Ph} . \mathrm{D}$ supervision. Commonwealth of Australia: Australian Government Publishing Service; 1994.

[58] Grant B, Graham A. Guidelines for discussion: a tool for managing postgraduate supervision. J Furth High Educ Scotl 1994; 20(1): 2330.

[59] Parry S, Hayden M. Supervising higher degree research students. An investigation of practices across a range of academic departments. Commonwealth of Australia: Australian Government Publishing Service; 1994.

[60] Piccinin SJ. Graduate student supervision: resources for supervisors and students. Triannual newsletter, Centre for development of teaching and learning (CDTL). CDTLink: University of Ottawa, Canada 2000.

[61] Armitage S, Rees C. Project supervision. Nurs Educ Today 1988; 8: 99-104.

[62] Guppy N, Trew M. Graduate student experience at UBC: an assessment - final report. University British Columbia, 1995.

This is an open access article licensed under the terms of the Creative Commons Attribution Non-Commercial License (http://creativecommons.org/licenses/by$\mathrm{nc} / 3.0 /$ ) which permits unrestricted, non-commercial use, distribution and reproduction in any medium, provided the work is properly cited. 